\title{
ESTRATÉGIAS DE DEFESA UTILIZADAS POR TRABALHADORES DE ENFERMAGEM ATUANTES EM PRONTO-SOCORRO
}

Jeanini Dalcol Miorin', Silviamar Camponogara², Camila Pinno3 Etiane de Oliveira Freitas ${ }^{3}$, Quézia Boeira da Cunha ${ }^{4}$, Gisele Loise Dias ${ }^{4}$

Objetivo: conhecer as estratégias defensivas utilizadas por trabalhadores de enfermagem atuantes em Pronto-Socorro. Metodologia: trata-se de um estudo descritivo com abordagem qualitativa. A coleta de dados ocorreu por meio de entrevista semiestruturada com 13 trabalhadores de enfermagem atuantes em um pronto-socorro, entre agosto e setembro de 2014. A análise dos dados seguiu os pressupostos da análise de conteúdo. Resultados: a partir da análise, emergiu a categoria: 'Estratégias de defesa utilizadas pela equipe de enfermagem', quais sejam: diálogo, enfoque nos aspectos técnicos do cuidado, estabelecimento de prioridades na rotina de serviço e desenvolvimento de atividades de lazer. Conclusão: a utilização de estratégias auxilia o trabalhador de enfermagem a vivenciar o trabalho de forma mais prazerosa.

Descritores: Trabalho; Enfermagem; Adaptação Psicológica; Serviços Médicos de Emergência.

\section{DEFENSE STRATEGIES USED FOR NURSING WORKERS IN EMERGENCY ROOM}

Objective: the study aimed to know the defensive strategies used by nursing staff working in emergency room. Methodology: this is a descriptive study with a qualitative approach. A data collection was performed by semi-structured interview with 13 nursing professionals who work at an emergency room, between August and September 2014. Results: the analysis followed the assumptions of thematic content analysis. From the data analysis emerged the category: "Defensive strategies used by nursing staff", which are dialogue, focus on technical aspects of care, setting priorities in the service routine and development of leisure activities. Conclusion: the use of strategies helps the nursing workers experience the work in a more pleasant way.

Descriptors: Work; Nursing; Adaptation, Psychological; Emergency Medical Services.

\section{ESTRATEGIAS DEFENSIVAS UTILIZADAS POR TRABAJADORES DE ENFERMERÍAACTIVOS EN PRIMEROS AUXILIOS}

Objetivo: conocer las estrategias defensivas utilizadas por trabajadores de enfermería que actúan en primeros auxilios. Metodología: investigación cualitativa y descriptiva. La recolección de datos ocurrió a través de entrevista semiestructurada con 13 trabajadores de enfermería que actúan en primeros auxilios, entre Agosto y Septiembre de 2014. El análisis siguió los supuestos del análisis de contenido temático. Resultados: a partir de la análisis de los datos ha surgido la categoría temática: "Estrategias defensivas utilizadas por el equipo de enfermería", que son el diálogo, el enfoque en los aspectos técnicos de la atención, establecimiento de prioridades en la rutina de servicio y desarrollo de actividades de ocio. Conclusión: el uso de estrategias ayuda a los trabajadores de enfermería experimentar el trabajo de modo más agradable.

Descriptores: Trabajo; Enfermería; Adaptación Psicológica; Servicios Médicos de Urgencia.

${ }^{1}$ Enfermeira. Residente do Centro Universitário Franciscano de Santa Maria. E-mail: jeaninimiorin@hotmail.com

2Enfermeira. Doutora em Enfermagem. Docente da Universidade Federal de Santa Maria (UFSM).

${ }^{3}$ Enfermeira. Doutoranda em Enfermagem. UFSM.

${ }^{6}$ Enfermeira. Mestranda em Enfermagem. UFSM. 


\section{ARTIGO 11}

\section{INTRODUÇÃO}

O trabalho é uma atividade importante para os seres humanos, servindo para obtenção de prazer, riqueza, acúmulo de bens materiais, dentre outros. Entretanto, também pode significar escravidão, exploração, sofrimento, estresse e, em consequência, resultar em agravos à saúde e até ocasionar a morte do trabalhador ${ }^{(1)}$. Essas repercussões positivas e negativas decorrem da própria natureza da atividade, da sua organização e das condições de trabalho(1).

O trabalho em ambiente hospitalar é rico, estimulante e heterogêneo, mas engloba, simultaneamente, atividades que envolvem sofrimento e dor ${ }^{(2)}$. Nos serviços de urgência e emergência, o ambiente é instável e agitado, as atividades são intensas e há uma demanda de pacientes em condições graves $^{(3)}$. Nesse contexto, o trabalhador lida com múltiplas situações, entre elas: número reduzido de funcionários, ambiente físico inadequado, falta de equipamentos e relacionamento conturbado com familiares ${ }^{(4)}$.

Essas experiências no cotidiano laboral podem interferir na vida social e emocional do trabalhador, pois trazem consigo sentimentos de "sobrecarga" e sofrimento. Nesse cenário, os trabalhadores de enfermagem têm um contato com o paciente e seus familiares, lidam com a morte e processo de luto da familia e com o sofrimento dos pacientes ${ }^{(3)}$.

O sofrimento desses profissionais diante da dor do outro é tão significativo que, se não forem encontradas formas de enfrentá-lo, o profissional poderánão sercapaz de desenvolver suas atividades rotineiras e pode vir a adoecer ${ }^{(5)}$. Assim, o profissional não gera uma descompensação psicopatológica (entendida como uma ruptura do equilibrio psíquico, que se manifesta pela eclosão de uma doença mental), quando o sujeito emprega defesas contra esse sofrimento, que the permitem controlá-lo(b)

As estratégias de defesa são meios utilizados, pelo trabalhador, para proteger-se do sofrimento; podem surgir frente a situações rotineiras e são vistas como uma maneira de não deixar que a assistência ao indivíduo influencie a vida do profissional fora da unidade hospitalar ${ }^{(5)}$.

Um estudo recente chegou a um resultado que indica que entre os profissionais existe uma forma de sofrimento relacionada a sentimentos internos, mobilizados a partir do encontro com a situação e a história do paciente ${ }^{(7)}$. Observouse, ainda, que a morte ou sofrimento de alguns pacientes constitui um processo que gera intenso desgaste e sofrimento no trabalho(7). Para compreender esses sentimentos, é importante considerar que o profissional e o paciente são seres humanos, o que resulta em uma estreita ligação entre o trabalho e o trabalhador, com contato direto com as vivências de sofrimento.
O presente estudo fundamentou-se na seguinte questão de pesquisa: quais estratégias defensivas são utilizadas por trabalhadores de enfermagem atuantes em pronto-socorro, diante do sofrimento presente nas diversas situações do cotidiano de trabalho? Objetivou-se conhecer as estratégias defensivas utilizadas por trabalhadores de enfermagem atuantes em pronto-socorro.

\section{METODOLOGIA}

Trata-se de um estudo descritivo com abordagem qualitativa, realizado em um Pronto-Socorro Adulto (PSAdulto) de um hospital de ensino, localizado na região Sul do Brasil. O setor dispõe de 22 leitos e conta com uma equipe de 44 trabalhadores de enfermagem. Os participantes do estudo foram enfermeiros e técnicos de enfermagem atuantes no PS-Adulto. Os seguintes critérios de inclusão foram eleitos: ser trabalhador de enfermagem e atuar, no setor, há mais de um ano. Foram excluídos os trabalhadores que estavam em afastamento por qualquer motivo, durante o período de coleta de dados. Ao total, foram entrevistados 13 participantes.

Os participantes foram selecionados mediante sorteio aleatório, técnica comumente utilizada em pesquisa qualitativa ${ }^{(8-10)}$. Ainda, manteve-se a proporcionalidade entre as categorias profissionais, até obedecer ao critério de saturação teórica dos dados ${ }^{(11)}$. Assim, foram entrevistados 13 trabalhadores de enfermagem, sendo cinco enfermeiros e sete técnicos de enfermagem.

A coleta dos dados ocorreu por meio de entrevista semiestruturada ${ }^{(12)}$, realizada mediante agendamento prévio, em local adequado. Os dados foram coletados durante os meses de agosto e setembro de 2014. As entrevistas foram gravadas e, posteriormente, transcritas e analisadas com base no referencial proposto para análise de conteúdo temática ${ }^{(13)}$. Foram observados os preceitos da Resolução 466 de dezembro de $2012^{(14)}$, sendo a pesquisa aprovada por Comitê de Ética em Pesquisa (CEP), sob o número 32475914.1.0000.5346. Identificados os participantes com o código E para enfermeiro e TE para técnico de enfermagem, seguidos por um número correspondente à ordem das entrevistas.

\section{RESULTADOS}

A partir da análise dos dados, emergiu a seguinte categoria temática: 'Estratégias de defesa utilizadas pela equipe de enfermagem.' Nessa categoria, os participantes mencionaram aspectos organizacionais, não vinculação com os pacientes, o diálogo entre a equipe e, ainda, atividades fora do cotidiano de trabalho, como lazer, religiosidade como estratégias de defesa. 
Estratégias de defesa utilizadas pela equipe de enfermagem

Os participantes indicaram que convivem com situações no trabalho, as quais levam ao sofrimento. Essas situações envolvem questões relacionadas à organização do trabalho, como falta de pessoal, sentimentos de angústia e frustração. Esses sentimentos estão articulados ao fato de se lidar com o sofrimento e a dor dos indivíduos, e a convivência com a morte. Para que esse sofrimento gerado não se instale permanentemente, os trabalhadores criam estratégias de defesa: Chega um acidente muito feio, um paciente todo traumatizado, com amputação de membro, muito ruim. Aquela imagem fica na tua cabeça, demora um tempão para ti conseguir eliminar aquela imagem. Então, se eu atendi de manhã, tudo vai ficar com aquilo relembrando o dia inteiro, da tarde, da noite que tu vai dormir ai tu tenta desviar o pensamento daquilo. (E-10); Às vezes tu ficas deprimido, se sente devendo, mas deixa, vai lá, atende outro e assim vai. (TE-O9).

Por outro lado, investir em afeto e criar laços tornase um fator de sofrimento. É necessário utilizar estratégias de defesa para lidar com a carga psíquica, sendo uma destas, distanciar $\circ$ afeto do trabalho, focando-se nas atividades técnicas: Não crio vinculo, amizade. Claro que educação, cumprimento tudo, mas não tenho nenhum vínculo maior, assim. Sempre cuidei, não me apego em nada,

faço o meu trabalho tranquilo, saio daqui esqueço a minha vida aqui dentro. (TE-08)

A não vinculação com o paciente oferece um alívio ao trabalhador, pois esse concentra-se no procedimento e defende-se da vinculação afetiva. Já a entrevistada TE-07 menciona que o trabalhador precisa ter em mente que o sofrimento é do paciente e não dele mesmo, e assim consegue criar uma espécie de barreira emocional, priorizando somente as atividades básicas e de reabilitação do paciente: No momento tu ficas chocada, mas dai tu começa a pensar: não, isso aí não é meu é do paciente. Tento tipo criar uma barreira, às vezes tu não consegue, mas, na maioria das vezes, tu tentas ficar mais dura e passa. Assim, não te envolver com o paciente, faz o que tem que fazer e sai, porque se tu ficar ali quando vê tu está chorando junto com o familiar. (TE-O7)

A questão da falta de profissionais, do excesso de pacientes, de recursos materiais escassos, também propiciam a criação de estratégias específicas para trabalhar nessas condições. Uma delas foi o estabelecimento de metas, ou seja, realizar as ações que reconhecem como prioritárias e, após, as outras consideradas menos emergenciais: Ver quais são as prioridades, quais pacientes que eu preciso atender, porque nesse universo de quase 50 eu não consigo ver todos. Se tu me perguntares quais são não sei nem o nome, só pela lista ali, então a gente tenta priorizar quem está grave, as emergências que chegam [...]. Então, eu comecei com o tempo assim, olha o que eu posso fazer para me manter com saúde mental aqui e trabalhando de forma correta, então priorizar, quem está grave. Então, quando eu chego naquele paciente eu priorizo, vou atender o seu João então, tudo que eu preciso fazer com ele [...]. (E-10);

A nossa prioridade é a emergência e que as medicações sejam feitas nos horários, ai depois disso tu tem a higiene do paciente, os cuidados com o paciente [...]. (TE-05)

$\mathrm{O}$ diálogo entre a equipe $\mathrm{e}$ o paciente foi referido como prática de enfrentamento e minimização do sofrimento. A seguir, identifica-se que o profissional, na intenção de amenizar seu sofrimento, diante da visualização da situação precária em que o paciente se encontra (internado em cadeiras de rodas ou macas), tenta dialogar: Eu tento conversar com a pessoa. Tentar explicar a situação que é assim, que é

o sistema. (TE-04)

Assim, o profissional sente-se 'aliviado', com a sensação de que não é culpado pela situação vivenciada pelo paciente. O diálogo entre a equipe também se mostrou como uma estratégia de defesa na luta contra as situações geradoras de sofrimento: Eu acho que a gente conversa entre a gente, as colegas e enfermeiras [...].(E-O2)

Nesse sentido, o diálogo oportuniza a compreensão mútua sobre os sentimentos vivenciados. Assim, essa verbalização, expressão dos sentimentos e "desabafo", gera alívio, diminuindo a tensão gerada pelo sofrimento vivenciado.

O lazer foi apontado, pelos entrevistados, como medida para diminuir os sentimentos negativos ocasionados pela atividade laboral, e para auxiliar no enfrentamento das adversidades. Procuro não ficar pensando, sai daqui e já vai fazer outra coisa, vai para academia. Já sai do ambiente, aí tira da cabeça aquilo. (E-O3); Eu leio bastante. Faço outras 


\section{ARTIGO 11}

leituras alternativas, fora da área da enfermagem, para tentar me ajudar, e isso tem me ajudado bastante. Também toda parte de fé, de espiritualidade, a não cair no que os meus outros colegas já tiveram, de cair em depressão profunda, de utilizar medicação. (E-10)

O apoio na fé e na espiritualidade foi apontado como estratégia para alívio das tensões associadas à dinâmica laboral. Conforme o relato a seguir, percebe-se que a entrevistada não é capaz de esquecer tudo que se passa durante o turno de trabalho, mas busca lidar com o sofrimento vivenciado. Eu sou assim, quando eu saio do hospital e chego na minha casa não vou te dizer que eu deixo o hospital e vou pra lá, é mentira, porque eu sonho com o hospital, com as bombas. Mas eu sei que se eu tiver no leito nove e ele for a óbito, eu sei que eu fiz tudo, tenho a minha consciência tranquila, mais importante que o dinheiro que tudo [...].(TE-O6)

O desenvolvimento de atividades alternativas favorece o nível de saúde, sobretudo mental, dos profissionais. Isso ocorre porque essas atividades transformam as energias comprometidas pelo ambiente instável do trabalho em aspectos saudáveis, contribuindo para o alívio da fadiga e do estresse provocado pelas situações de sofrimento.

\section{DISCUSSÃO}

$\mathrm{Na}$ evolução dos estudos sobre a psicodinâmica do trabalho, a questão do sofrimento passou a ocupar uma posição relevante. Otrabalho tem efeitos sobre o sofrimento psíquico, contribuindo para agravá-lo, levando progressivamente o indivíduo à loucura, ou para transformá-lo, ou subvertê-lo em prazer, a tal ponto que o individuo que trabalha preserva melhor a sua saúde do que aquele que não trabalha ${ }^{(6)}$. Isso significa que o trabalho ora é patogênico, ora estruturante, dependendo de uma dinâmica complexa, cujas principais etapas são identificadas e analisadas pela psicodinâmica do trabalho(6).

Percebe-se a importância desses trabalhadores reconhecerem os fatores geradores de sofrimento no seu ambiente de trabalho, e suas consequências. Assim, a forma como cada trabalhador lida com tais situações, desempenha uma função importante no seu processo de saúde-doença ${ }^{(15)}$.

As estratégias de defesa são simples ou complexas, diversas e únicas, podendo contribuir para tornar aceitável aquilo que não deveria sê-lo. São necessárias para a proteção da saúde mental contra os efeitos deletérios do sofrimento, mas podem funcionar como uma armadilha, que insensibiliza contra aquilo que faz sofrer ${ }^{(6)}$.

Essas estratégias podem repercutir nas possibilidades de modificação das situações de trabalho(16). Estudo(6) constatou que, em vez de adoecer, em sua maioria, os trabalhadores permanecem na normalidade, a qual é interpretada como o resultado de uma composição entre o sofrimento e a luta (individual e coletiva) contra o sofrimento no trabalho. Portanto, normalidade não implica ausência de sofrimento, ela é o resultado alcançado na luta contra a desestabilização psíquica provocada pelas pressões do trabalho(6).

A afetividade é o modo pelo qual o próprio corpo vivencia seu contato com o mundo, estando na base da subjetividade. Negar ou desprezar a afetividade é nada menos que negar ou desprezar no homem o que é sua humanidade, é negar a própria vida(b). Entretanto, os profissionais acreditam que para desempenhar sua prática profissional devem se manter distantes, evitando construir vínculos com os pacientes e familiares, para evitar o sofrimento(17).

Assim, a estratégia de negar a afetividade e direcionar o cuidado às atividades técnicas é contraditória, pois pode gerar indiferença e descaso com a vida. Essas estratégias não devem ser condenadas, pois são necessárias à proteção da integridade psíquica e

somática do trabalhador(6).

Uma outra estratégia de defesa identificada foi o diálogo. Quando esse ocorre entre profissional de saúde e paciente com o objetivo de ajudá-lo a enfrentar seus problemas, relacionar-se com os demais, ajustar o que não pode ser mudado e enfrentar os bloqueios à autorrealização, é denominada comunicação terapêutica ${ }^{(18)}$. Ressalta-se a importância de criar espaços de escuta em grupo, nas instituições de formação e atuação desses trabalhadores, para que possam se expressar e buscar coletivamente estratégias para enfrentamento das adversidades no cotidiano laboral ${ }^{(3)}$.

Assim, propiciar que os trabalhadores de saúde vivenciem esses momentos de diálogo contribui para melhora de sua saúde mental, pois, pelo dever do ofício, este lida com o sentimento de angústia relacionado a situações de precariedade do existir humano ${ }^{(19)}$. A realização de atividades alternativas ajuda a esquecer os problemas vivenciados no 
cotidiano laboral, esse tempo livre é essencial para o nosso desenvolvimento(20).

A espiritualidade vem sendo reconhecida como uma das estratégias de enfretamento encontradas pelos profissionais (21). O significado da dimensão espiritual para cada trabalhador de enfermagem tem relação direta com o cuidado prestado interferindo nas questões de empatia e nas próprias questões existenciais ${ }^{(22)}$

O estudo realizado apresentou limitações importantes com relação ao número de entrevistados; dessa forma a partir dessa pesquisa tem-se como perspectiva a continuação de diferentes formas de abordagens a este tema de estudo.

\section{CONCLUSÃO}

Os resultados mostraram que os participantes investigados utilizam estratégias de defesa diante de situações que geram ou que tenham potencial de gerar sofrimento; assim, não são passivos diante dos fatores organizacionais desestabilizantes. Eles protegem-se, utilizando o diálogo entre a equipe, estabelecendo metas, focando-se nos procedimentos técnicos e buscando realizar atividades alternativas, fora do ambiente hospitalar.

Nesse sentido, a identificação das situações geradoras de sofrimento e das estratégias de enfrentamento utilizadas nesse processo e de sua repercussão nas atividades laborais corresponde a um importante agente de mudança. O desenvolvimento de estratégias para minimizar o sofrimento pode tornar o cotidiano dos trabalhadores de enfermagem mais produtivo e menos desgastante, valorizando-o no que se refere aos aspectos humanos.

\section{REFERÊNCIAS}

1. Martins JT, Bobroff MCC, Ribeiro RP, Robazzi MLCC, Marziale MHP, Haddad MCL. Significados de cargas de trabalho para enfermeiros de Pronto Socorro/Emergência. Cienc Cuid Saude. 2013; 12(1): 40-6.

2. Almeida PJS, Pires DEP. O trabalho em emergência: entre o prazer e o sofrimento. Rev Eletr Enf. 2007; 9(3): 617-29.

3. Garcia AB, Dellaroza MSG, Gvozd R, Haddad, MCL. O sofrer no trabalho: sentimentos de técnicos de enfermagem do pronto-socorro de um hospital universitário. Cienc Cuid Saude. 2013; 12(3): 416-23.

4. Barbosa KP, Silva LMS, Fernandes MC, Torres RAM, Souza RS. Processo de trabalho em setor de emergência de hospital de grande porte: a visão de trabalhadores de enfermagem. Rev Rene. Fortaleza. 2009; 10(4): 70-6.

5. Salimena AMO, Teixeira SR, Amorin TV, Paiva ACPO, Melo MCSC. Estratégias de enfrentamento usadas por enfermeiros ao cuidar de pacientes oncológicos. Rev Enferm UFSM. 2013; 3(1): 8-16.

6. Dejours CA. A banalização da injustiça social. Rio de Janeiro: Fundação Getúlio Vargas: 1999.

7. Garcia AB, Dellaroza, MSG., Gvozd R, Haddad MCL. O sofrer no trabalho: sentimentos de técnicos de enfermagem do pronto-socorro de um hospital universitário. Rev Cienc Cuid Saúde. 2013;12(3): 416-23

8. Machado LM, Colomé JS; Silva, RM da; Sangoi TP, Freitas, NQ. Significados do fazer profissional na estratégia de saúde da familia: atenção básica enquanto cenário de atuação. Rev. pesqui. cuid. fundam.2016:8(1):4026-35.

9. Furlan MCR, Gonzales RIC, Marcon SS. Desempenho dos serviços de controle da tuberculose em municipios do Paraná: enfoque na familia. Rev Gaúcha Enferm. 2015;36(esp): 102-10.

10. Valenca MS; cezar-vaz MR, Brum CB, Silva PEA da. O processo de detecção e tratamento de casos de tuberculose em um presidio. Ciênc. saúde coletiva [online]. 2016;21(7):2111-22.

11. Fontanella BJB, Ricas J, Turato ER. Amostragem por saturação em pesquisas qualitativas em saúde: contribuições teóricas. Cad. Saúde Pública. 2008; 24(1): 17-27.

12. Gil AC. Métodos e técnicas de pesquisa social. 5a ed. São Paulo: Atlas: 2006

13. Minayo MCS. O desafio do conhecimento: pesquisa qualitativa em saúde. 14ạ ed. São Paulo: Hucitec: 2014
14. Brasil. Ministério da Saúde. Conselho Nacional de Saúde. Resolução no 466, de 12 de dezembro de 2012. Brasilia; 2012.

15. Melo MV. Estresse dos profissionais de saúde nas unidades hospitalares de atendimento em urgência e emergência. Cadernos de Graduação Ciências Biológicas e da Saúde Facipe. 2013; 1(2): 35-42.

16. Faria CJ, Leal DHMS, Oliveira SNVD de. Prazer e sofrimento: avaliação de enfermeiros intensivistas à luz da psicodinâmica do trabalho. Esc. Anna Nery [Internet]. 2014 Mar [cited 2016 May 09]:18(1):90-95.Disponivel em: $\quad$ http://www.scielo.br/scielo.php?script=sci_arttextEpid=S141481452014000100090 \&lng=en.

17. Abrão FM da S, Góis AR da S, Souza MSB de, Araujo RA de, Cartaxo CMB Oliveira DC de. Representações sociais de enfermeiros sobre a religiosidade ao cuidar de pacientes em processo de morte Rev bras enferm. [Internet]. 2013 Oct [cited 2016 May 03] : 66( 5 ): 730-737. Disponivel em: http://www.scielo.br/scielo.php?script=sci_arttextepid=S0034716720130005000148 lng=en.

18. Damasceno MMC, Zanetti ML, Carvalho EC, Teixeira CRS, Araújo MFM, Alencar AMPG. Therapeutic communication between health workers and patients concerning diabetes mellitus care. Rev. Latino-Am. Enfermagem [Internet]. 2012 [citado 2015 Jun 14]: 20(4): 685-92. Disponivel em: http://www.scielo.br/scielo.php?script=sci_arttext\&pid=S010411692012000400008 \&lng=pt.

19. Silva LC. O sofrimento psicológico dos profissionais de saúde na atenção ao paciente de câncer. Psicol. Am. Lat. [online]. 2009 [citado 2015 Ago 05] 16: 0-0. Disponivel em: <http://pepsic.bvsalud.org/scielo.php?script=sci_ arttext\&pid=S1870-350X2009000100007\&lng=pt\&nrm=iso>. ISSN 1870$350 X$

20. Maia DAC, Maciel RHMO, Vasconcelos JA, Filho JOV. Acadêmicos de Medicina: Sua Relação com o Ócio e a Prática de Atividade Física como Combate à Ansiedade e ao Estresse. Cadernos ESP. 2011; 5(1): 62-73.

21. Moreira AO, Sousa HA, Ribeiro JÁ. Vivências e estratégias defensivas dos enfermeiros frente ao cuidado em unidade de terapia intensiva. Rev Enferm UFSM [Internet]. 2013 [acesso em 2015 abr 9];3(1):102-11. Disponivel em: http://cascavel.ufsm.br/revistas/ojs- 2.2.2/index.php/reufsm/article/ view/7207/pdf.).

22. Penha RM, Silva MJP. Meaning of spirituality for critical care nursing Texto Contexto Enferm. 2012; 21(2): 260-8. 